\title{
Case Studies in Clinical Psychology: Are We Giving up a Publication Type and Methodology in Research on and Teaching of Psychopathology and Psychotherapy?
}

\author{
Dorothea Krampen ${ }^{1}$ \& Günter Krampen ${ }^{2,3}$ \\ ${ }^{1}$ Department of Educational Psychology, Goethe University Frankfurt, Frankfurt (Main), Germany \\ ${ }^{2}$ Department of Clinical Psychology, University of Trier, Trier, Germany \\ ${ }^{3}$ Leibniz Institute for Psychology Information (ZPID), Trier, Germany \\ Correspondence: Dorothea Krampen, Department of Educational Psychology, Goethe University Frankfurt, \\ 60629 Frankfurt (Main), Germany. Tel: 49-69-798-35382. E-mail: krampen@paed.psych.uni-frankfurt.de
}

Received: May 30, 2016

Accepted: July 9, 2016

Online Published: August 4, 2016

doi:10.5539/ijps.v8n3p173

URL: http://dx.doi.org/10.5539/ijps.v8n3p173

\begin{abstract}
Scientometric results on publication trends in clinical psychology, which refer to publication type and methodology of case studies/reports, are presented. Absolute and relative frequencies of clinical case studies are identified for the segment "mental and behavioral disorders" in MEDLINE (ICD-10 Chapter V [F]) as well as for clinical psychology publications documented in PsycINFO and PSYNDEX in 40 publication years (1975-2014). Results show an increase of the absolute number of published case studies documented in MEDLINE and PsycINFO (but not in PSYNDEX), which is highly correlated with the total increase of clinical psychology publications in both databases. Relative frequencies show another picture, namely a drop of the percentage of case studies on mental and behavioral disorders in MEDLINE, and a sharp drop in PSYNDEX since the 1980s. The trend for the relative frequency of case studies within all publications on clinical psychology documented in PsycINFO is V-shaped with 6\% in the 1970 s, 3\% in the early 1990s, and 4-5\% after the millennium. Pros and cons of case studies in clinical psychology research and education are discussed. Qualitative and quantitative case study methodologies are distinguished with respect to the phases of clinical trials and observational studies in evidence-based and empirically supported psychotherapy. Subsequently, methodological constraints are balanced with specific values in clinical training, applied research, and innovative research on the symptomatology, etiology, and classification of mental disorders as well as on combined and/or integrative treatment techniques and methods.
\end{abstract}

Keywords: case study, clinical psychology, psychopathology, psychotherapy, scientometrics

\section{Introduction}

Quite recently, Glänzel and Schubert (2015) presented scientometric results on the immense increase of case studies in scientific publications since the late 1970s. They analyzed the numbers of articles having the term "case study" or "case report" in their titles "as included in the Thomson Reuters Web of Science Core Collection database" (p. 1) in the publication years 1975 to 2013. The growth rate described starts at about 1,000 case studies/reports per year in the late 1970s and ends in the early $2010 \mathrm{~s}$ at about 7,000 per year with "the doubling time of case studies (...) as short as 6 years by the 2000's" (Glänzel \& Schubert, 2015, p. 1). In addition, they mention that "the vast majority (more than two third) of the case studies/case reports was found to be published in the medical, biomedical and biological sciences followed by social sciences and the humanities and then by environmental sciences engineering (...) and geosciences” (p. 2). Although the specific data for psychology are not presented, psychological case studies/reports are included, because - following the structure and organization of the Web of Science (WoS) — they are subsumed to medical, biomedical, and/or social sciences.

The present scientometric analyses take a closer and more differentiated look at the number of case studies/reports published in clinical psychology in the last 40 years. Scientometrically based developmental trends from 1975 to 2014 are shown. In clinical psychology the methodology of case studies/reports and the corresponding publication type have a long history reaching back to its roots in the 19th century. There are masterpieces of clinical case studies/reports (e.g., Falret, 1854; Freud, 1905, 1909a, 1909b, 1918, 1920; Jones, 
1924; Watson \& Rayner, 1920). These classics are reprinted, translated over and over again and sometimes shortened in doing so (e.g., Freud, 1909a/1928, 1909b/1971, 1905/1993; Lesser \& Schoenberg, 1999; Rolls, 2015; Watson \& Rayner, 1920/2000). They are used in clinical psychology education and psychotherapy training, and they are cited and reflected in research papers and books up to now (e.g., Lesser \& Schoenberg, 1999; Pflug et al., 2012).

The reason for the extensive use of these case studies/reports is not only their concreteness and contextuality, but - much more than this - their innovative contributions to analyses and differential diagnosis of mental disorders as well as to combined, integrative, and/or more differentiated psychotherapy (and other) treatment techniques and methods. For example, development and dissemination of cognitive psychotherapy (e.g., Beck et al., 1992; Berk et al., 2004; Kovacs \& Beck, 1978), client-centered psychotherapy (e.g., Lewis et al., 1959; Rogers, 1989) as well as applied relaxation therapy and cognitive-behavioral psychotherapy (e.g., Johansson \& Öst, 1981; Öst, 1985, 1992; Öst \& Käll, 1977) were initiated and strengthened by the publication of clinical case studies/reports. Nowadays, case studies/reports often abandon the classical interpretative, narrative, i.e., qualitative approach in favor of a more quantitative, systematic single-case (sometimes experimental) or a combined methodology (for comprehensive overviews on single-case experimental designs, see, e.g., Perone \& Hursh, 2013; Yin, 2014).

Extending beyond a more or less dominant consensus on the interchangeability of the terms "case report" and "case study" (e.g., Crowe et al., 2011; Glänzel \& Schubert, 2015), it is sometimes-mainly and primarily in medical publications - specified that case reports are purely descriptive, while case studies "add an element of analysis" (Glänzel \& Schubert, 2015, p. 1), which may refer, for example, to theoretical arguments, the integration of psychometric or biopsychological measurements, and/or systematic treatment designs (e.g., systematic interventional blending-masking-designs; ABABABB). However, no such distinction is considered in the following, as we maintain the terminology of the APA Thesaurus of Psychological Index Terms (Gallagher Tuleya, 2007) and the APA Databases Methodology Field Values for defining "clinical case study" as "Case reports that include disorder, diagnosis, and clinical treatment for individuals with mental or medical illnesses" (p. 1, 2nd line top down; http://www.apa.org/pubs/databases/training/method-values.aspx). Thus, case studies as well as case reports from clinical psychology are included in the scientometric analyses, but-in some short supplemental analyses - they are clearly distinguished from "non-clinical case studies", which are defined as "Document consisting of non-clinical or organizational case examples of the concepts being researched or studied. The setting is always non-clinical and does not include treatment-related environments" (p. 1, 16th line top down; http://www.apa.org/pubs/databases/training/method-values.aspx).

The starting point of our research question is formed by the scientometric results from Glänzel and Schubert (2015) on the vast increase of publications on case studies/reports in many sciences. We focus on the same time period (extended by one publication year) as Glänzel and Schubert, but we do not use the broadly scoped, "all" sciences covering Web of Science (WoS) as database. Rather, we use domain-specific databases for psychology publications (i.e., PsycINFO and PSYNDEX) and-in addition - the segment of MEDLINE, which refers to "mental and behavioral disorders". This segment of MEDLINE covers medical and clinical psychology publications on mental and behavioral disorders listed in chapter V (F) of the International Classification of Diseases (ICD-10, Version 2016; retrieved from http://apps.who.int/classifications/icd10/browse/2016/en\#/V). Chapter V (F) specifies a broad range of conditions that are typically associated with a disruption in normal thinking, feeling, and behavior producing either distress or impairment of daily functioning. Examples include mood disorders such as depression, disorders caused by substance abuse, or personality disorders. The consideration of three different databases further allows for comparisons of the coverage between the databases and correlation analyses for the growth rates of the publications documented in the databases. This may provide information about the utility of each database for an as far as possible complete scientific publication seeking in clinical psychology.

\subsection{Research Questions}

The main research question focuses on the developmental trends of the number of case studies documented in the three databases for the 40 publication years between 1975 and 2014. Analyses include the absolute frequencies and - in addition to and beyond Glänzel and Schubert (2015) - the relative frequencies to consider the hypothesis that the growth rate (or decline) of case studies may be an artifact, which can be explained by a general increase (or-this is unlikely - drop) of all publications in clinical psychology or on mental disorders, respectively. Supplemental research questions correspond to (1) comparisons between the three databases used and (2) the frequency of non-clinical case studies/reports in other than clinical subdisciplines of psychology (e.g., industrial and organizational psychology, educational psychology, etc.). 


\section{Method}

\subsection{Databases}

All data used in the following derive from MEDLINE, PsycINFO, and PSYNDEX. MEDLINE is the leading international database for medical science publications (including clinical psychology to some extent); PsycINFO and PSYNDEX are databases for psychology publications and for publications with psychological significance from neighboring disciplines, such as education, sociology, and linguistics. From the basic population of these databases publications were selected by means of search strategies, which refer to clinical psychological literature published between 1975 and 2014.

The samples from PsycINFO and PSYNDEX comprise publications documented in the two broad classification codes (CC; Thesaurus of Psychological Index Terms; Gallagher Tuleya, 2007) of clinical psychology referring to "Psychological \& Physical Disorders" $\left(\mathrm{CC}=32^{*}\right.$; the asterisk includes all subcategories of the code) and "Health \& Mental Health Treatment \& Prevention" (CC=33*; Gallagher Tuleya, 2007). The sample from MEDLINE refers to documents, which are explicitly subsumed to the segment "mental and behavioral disorders", and thereby correspond to chapter V (F) of the International Classification of Diseases (ICD-10, Version 2016; retrieved from http://apps.who.int/classifications/icd10/browse/2016/en\#/V).

$M E D L I N E \circledast$. This database "contains journal citations and abstracts for biomedical literature from around the world" (retrieved from https://www.nlm.nih.gov/bsd/pmresources.html). PubMed ${ }^{\circledR}$ is a free search engine accessing the MEDLINE database. It provides access to MEDLINE and links to full-text content when possible (retrieved from http://www.ncbi.nlm.nih.gov/pubmed). Currently, MEDLINE/PubMed comprises more than 25 million documents from all medical subdisciplines including psychiatry, neurology, etc. Publications from clinical psychology are incorporated as well. Producer/host is the National Library of Medicine (NLM, Bethesda, MD, US).

PsycINFO®. The American Psychological Association (APA, Washington, DC, US) produces PsycINFO and features it as an international database going back to 1806 . However, PsycINFO is dominated markedly by Anglo-American, English-language publications ( $>90 \%$ of the documents; $<2 \%$ of the documents are Englishand German-language publications from the German-speaking countries; Krampen, 2009) and its coverage of psychology publications steadily improves, but only after the late 1970s in the context of digitalization. In autumn 2015 there are about 4 million documents in PsycINFO (retrieved, e.g., from http://www.apa.org/pubs/databases/psycinfo/index.aspx).

PSYNDEX ${ }^{\circledR}$. This database, developed and hosted by the Leibniz Institute for Psychology Information (ZPID; Trier, Germany), is the complementary, exhaustive database for German- and English-language publications in psychology and its neighboring disciplines in the German-speaking countries, i.e., Germany, Austria, Switzerland, Liechtenstein, and Luxembourg. In Germany, Austria, and Liechtenstein German is the official language. In Switzerland and Luxembourg German is one of three different official languages with large dissemination and usage. Documentation in PSYNDEX starts with the publication year 1977 (for German psychological tests: 1945). In autumn 2015 there are about 300,000 documents in PSYNDEX (retrieved, e.g., from http://www.zpid.de, http://www.MEDPILOT.de, or http://www.pubpsych.de). Thus, in absolute numbers, PsycINFO includes 13.3 times more documents than its European counterpart PSYNDEX.

\section{2 (Re-)Search Strategies}

Publications on mental and behavioral disorders were searched in MEDLINE by means of the terminology used in chapter V (F) of the International Classification of Diseases (ICD-10, Version 2016; retrieved from http://apps.who.int/classifications/icd10/browse/2016/en\#/V). Moreover, to allow for comparisons between the different medical subdisciplines, searches included all 21 main disease categories, i.e., chapters, of the ICD-10. Searches referred to the disease categories explicitly named in the chapter headings and "related terms" (specific diseases), but not to specific diagnoses at the keyword level (because this would imply several hundred terms solely for chapter V [F] of ICD-10 and very much more for the other ICD-10 chapters). Searches were implemented at the level of "Keywords" (MP [multi-purpose]) and of "All Fields" (AF), combined with a logical "OR". The same logical-or search strategy was used to identify all case studies and case reports documented in MEDLINE. Last searches combined the searches for ICD-10 disease categories (i.e., the 21 chapters) with the search for case studies/reports by a logical "AND" for the publication years 1975 to 2014.

The two subsets of clinical psychology publication documents in PsycINFO and PSYNDEX were searched by means of the classification codes "Psychological \& Physical Disorders" $(\mathrm{CC}=32 *)$ and "Health \& Mental Health Treatment \& Prevention" (CC=33*; see Gallagher Tuleya, 2007) with the logical operator "OR". Furthermore, 
scientometric analyses included the search fields "Year of Publication" (YR), "Subject Headings" (SH), and "Keywords" (MP) (Gallagher Tuleya, 2007). As for MEDLINE, idem logical-or search strategy was used to identify all case studies and case reports documented in PsycINFO and PSYNDEX. Logical-or searches referred to keywords (MP), all fields (expand) and the field "Methodology" (MD), which differs between clinical and non-clinical case studies/reports. Last searches combined the searches for clinical psychology publications with the search for case studies/reports by a logical "AND" for the publication years 1975 to 2014. All searches were performed in October 2015.

\section{Results}

To get an impression of the quantity of case studies in clinical publications on mental and behavioral disorders in comparison to the quantity in other medical subdisciplines, we initially present scientometric results on the absolute numbers and the relative frequencies of clinical case studies within the 21 different disease categories referring to the ICD-10 chapters in the MEDLINE database. Then we focus on the absolute growth rate of case studies published in clinical psychology in the psychological databases PsycINFO and PSYNDEX. Coverage and correlation analyses for these data are shown. The necessary relativization of the absolute numbers of case studies upon the absolute total numbers of clinical psychology publications in 1975 to 2014 is followed by an excursus on the publication trends of non-clinical case studies/reports in other subdisciplines of psychology.

\subsection{Clinical Case Studies in Different Medical Subdisciplines (MEDLINE)}

Results on absolute numbers and relative frequencies of case studies published in different medical subdisciplines are presented in Table 1 with reference to (total) MEDLINE documentations in the publication years 1945 to 2014. Because MEDLINE features backfiles to 1945, this (extended) time window is considered first. It must be noted that the rather coarse-grained search routines described above include only around 4.5 million of the 25 million documents in MEDLINE (i.e., 18\%). This seems to be a tiny little bit, but it should be considered that these publications constitute the core diseases listed in the 21 different ICD-10 chapters with a very high precision and horizontal differentiation.

Table 1. Absolute $(f)$ and relative frequencies (\%) of publications documented in MEDLINE on all ICD-10 chapters (Version 2016) ${ }^{\mathrm{a}}$ and of publications on case studies/reports within the chapters in the publication years 1945-2014

\begin{tabular}{|c|c|c|c|c|c|}
\hline \multicolumn{2}{|c|}{ ICD-10 chapter $^{\mathrm{b}}$} & \multicolumn{2}{|c|}{ Total chapter } & \multicolumn{2}{|c|}{ Case studies } \\
\hline No. & Heading $^{\mathrm{c}}$ & $f$ & $\%$ & $f$ & $\%$ \\
\hline I & Certain infectious \& parasitic diseases & 869,251 & 19.6 & 92,301 & 10.6 \\
\hline II & Neoplasms & 856,846 & 19.4 & 71,370 & 8.3 \\
\hline III & $\begin{array}{l}\text { Diseases of the blood \& blood-forming organs \& involving } \\
\text { immune mechanisms }\end{array}$ & 83,410 & 1.9 & 4,780 & 5.7 \\
\hline IV & Endocrine, nutritional \& metabolic diseases & 85,726 & 1.9 & 2,885 & 3.4 \\
\hline V & Mental \& behavioral disorders & 151,467 & 3.4 & 6,813 & 4.5 \\
\hline VI & Diseases of the nervous system & 38,871 & 0.9 & 3,906 & 10.4 \\
\hline VII & Diseases of the eye and adnexa & 163,379 & 3.4 & 29,123 & 17.8 \\
\hline VIII & Diseases of the ear \& mastoid process & 48,718 & 1.1 & 8,288 & 17.0 \\
\hline IX & Diseases of the circulatory system & 154,122 & 3.5 & 5,771 & 3.7 \\
\hline $\mathrm{X}$ & Diseases of the respiratory system & 19,928 & 0.5 & 651 & 3.3 \\
\hline XI & Diseases of the digestive system & 38,315 & 0.9 & 2,147 & 5.6 \\
\hline XII & Diseases of the skin \& subcutaneous tissue & 79,781 & 1.8 & 21,620 & 27.1 \\
\hline XIII & Diseases of the musculoskeletal system \& connective tissue & 99,818 & 2.2 & 12,866 & 12.9 \\
\hline XIV & Diseases of the genitourinary system & 484,363 & 10.9 & 57,594 & 11.9 \\
\hline $\mathrm{XV}$ & Pregnancy, childbirth \& the puerperium & 787,684 & 17.8 & 3,777 & 4.2 \\
\hline XVI & Certain conditions originating in perinatal period & 87,867 & 2.0 & 79,910 & 10.1 \\
\hline XVII & $\begin{array}{l}\text { Congenital malformations, deformations \& chromosomal } \\
\text { abnormalities }\end{array}$ & 143,523 & 3.3 & 17,012 & 11.8 \\
\hline XVIII & Abnormal clinical \& laboratory findings & 43 & 0.0 & 15 & 34.9 \\
\hline XIX & Injury, poising \& other consequences of external causes & 582,550 & 13.2 & 70,856 & 12.1 \\
\hline XX & External causes of morbidity \& mortality & 32,523 & 0.1 & 380 & 1.2 \\
\hline XXI & Factors of health status \& health service use & 159,766 & 3.6 & 2,494 & 1.6 \\
\hline$\Sigma$ & Chapters I-XXI in total & $4,427,041$ & 100 & 446,780 & 10.1 \\
\hline
\end{tabular}


ahttp://apps.who.int/classifications/icd10/browse/2016/en\#/V.

${ }^{\mathrm{b}}$ Including multiple classifications to two or more chapters (e.g., in publications on comorbidities or multimorbidity).

${ }^{\mathrm{c}}$ Original ICD-10 headings might be shortened.

There are 151,467 publications documented in MEDLINE, which refer to mental and behavioral disorders and - thus - chapter V (F) of ICD-10. This corresponds to 3.4\% of the MEDLINE documents analyzed and constitutes rank 8.5 in the rank order of the 21 ICD-10 chapters (see Table 1). Much higher percentages and ranks are on hand for "certain infectious and parasitic diseases" (19.6\%; 1st rank) and "neoplasms" (19.4\%; 2nd rank). For the results on all other MEDLINE segments (ICD-10 chapters), see Table 1. We would like to point out the very small number of documents in chapter XVIII, which pools all "symptoms, signs and abnormal clinical and laboratory findings, not elsewhere classified" and takes the last, the 21 st rank of all ICD-10 chapters.

As shown in Table 1, there are 446,780 case studies/reports in the MEDLINE segments of current interest. This constitutes $24.4 \%$ of all 1,830,454 case studies/reports documented in MEDLINE, which-keeping the search strategy with concentration on ICD-10 chapters in mind - seems to be a fairly good proportion. Over all 21 ICD-10 chapters $M=10.1 \%$ of the publications are case studies/reports. However, the proportion varies strongly between the 21 chapters (see Table 1): $4.5 \%$ percent of all publications on mental and behavioral disorders documented in MEDLINE are case studies (15th rank). Chapter XVIII ("symptoms, signs and abnormal clinical and laboratory findings, not elsewhere classified") shows - not surprisingly - the highest quota and comes in first (1st rank). Psychologically more interesting are the high quota of case studies/reports within publications on "diseases of the skin and subcutaneous tissue" (27\%), "diseases of the eye and adnexa" (18\%), and "diseases of the ear and mastoid process" (17\%), which cover constraints, diseases, and symptoms of three dominant exteroceptive sensory organs (visual, auditory, and tactile sense). These senses are most prevalent in everyday life person-environment interactions, while the sense of smelling (subcategorized to chapter X "diseases of the respiratory system") and the sense of taste (subcategorized to chapter XI "diseases of the digest system") mainly become prevalent when in conscious action, e.g., when there is something special (positive or negative - perhaps - alarming) in the air or on the tongue/palate.

With regard to our research question on the coverage of MEDLINE for publications on mental and behavioral disorders it can be noted that most of these MEDLINE documents refer to publications after 1974 (85\%), while the small rest was published between 1945 and 1974. The same holds for case studies/reports within the publications on mental and behavioral disorders: only $2 \%$ of them were published between 1945 and 1974. This may be interpreted as hinting at (1) a rather lately admission of these publications in MEDLINE and (2) an increasing coverage over the years.

\subsection{Absolute Numbers of Clinical Case Studies Published (MEDLINE, PsycINFO, and PSYNDEX)}

Table 2 presents the numbers of publications documented in MEDLINE on ICD-10 chapter V (F) "mental and behavioral disorders", on clinical psychology in PsycINFO and PSYNDEX as well as the numbers of publications on case studies/reports within the chapter or clinical psychology, respectively. To allow for comparisons between the three databases, the time window is standardized to the publication years 1975 to 2014; to support a clear line of reasoning, data are aggregated in 5-year intervals (quintiles) of the publication years 1975 to 2014. 
Table 2. Numbers of publications documented in MEDLINE on ICD-10 chapter "mental and behavioral disorders" (Version 2016) a , on clinical psychology in PsycINFO and PSYNDEX as well as of publications on case studies/reports within the chapter or clinical psychology, respectively, in quintiles of the publication years 1975-2014

\begin{tabular}{|c|c|c|}
\hline Database & Total number $(f)$ & Case studies $(f)$ \\
\hline \multicolumn{3}{|c|}{ MEDLINE: Chapter Mental \& Behavioral Disorders } \\
\hline 1974-1979 & 10,211 & 667 \\
\hline $1980-1984$ & 9,203 & 813 \\
\hline 1985-1989 & 9,678 & 717 \\
\hline 1990-1994 & 10,622 & 721 \\
\hline 1995-1999 & 12,034 & 726 \\
\hline $2000-2004$ & 17,547 & 822 \\
\hline 2005-2009 & 26,834 & 985 \\
\hline $2010-2014$ & 32,347 & 988 \\
\hline \multicolumn{3}{|c|}{ PsycINFO: Clinical psychology $\left(\mathrm{CC}=32 * \text { or } 33^{*}\right)^{\mathrm{b}}$} \\
\hline 1974-1979 & 44,097 & 2,668 \\
\hline $1980-1984$ & 62,374 & 3,211 \\
\hline 1985-1989 & 108,327 & 4,765 \\
\hline 1990-1994 & 130,701 & 3,897 \\
\hline 1995-1999 & 139,238 & 6,543 \\
\hline $2000-2004$ & 184,758 & 9,189 \\
\hline 2005-2009 & 301,438 & 13,344 \\
\hline $2010-2014$ & 372,315 & 15,962 \\
\hline \multicolumn{3}{|c|}{ PSYNDEX: Clinical psychology $(\mathrm{CC}=32 * \text { or } 33 *)^{\mathrm{b}}$} \\
\hline 1974-1979 & 2,681 & 197 \\
\hline $1980-1984$ & 9,303 & 497 \\
\hline $1985-1989$ & 16,562 & 874 \\
\hline 1990-1994 & 20,976 & 1,071 \\
\hline 1995-1999 & 22,222 & 931 \\
\hline $2000-2004$ & 21,381 & 195 \\
\hline $2005-2009$ & 23,094 & 42 \\
\hline 2010-2014 & 25,113 & 30 \\
\hline
\end{tabular}

ahttp://apps.who.int/classifications/icd10/browse/2016/en\#/V.

${ }^{\mathrm{b}} \mathrm{CC}=$ Classification codes (Thesaurus of Psychological Index Terms; Gallagher Tuleya, 2007).

\subsubsection{Increase of Publication Output}

There are huge increases in the numbers of publications documented in the three databases on mental and behavioral disorders and clinical psychology, respectively. This is well known for all sciences and corresponds to extended personnel, organizational, and financial resources of sciences in many countries between 1975 and 2014. In addition, this trend was and still is reinforced strongly by computer technology, the internet, and digitalization, for which essential innovations took place in this time period. MEDLINE documents tripled between the late 1970s and the early 2010s, PsycINFO documents increased 12 times, and PSYNDEX documents increased about 10 times (for a graphical illustration, see Figure 1). 


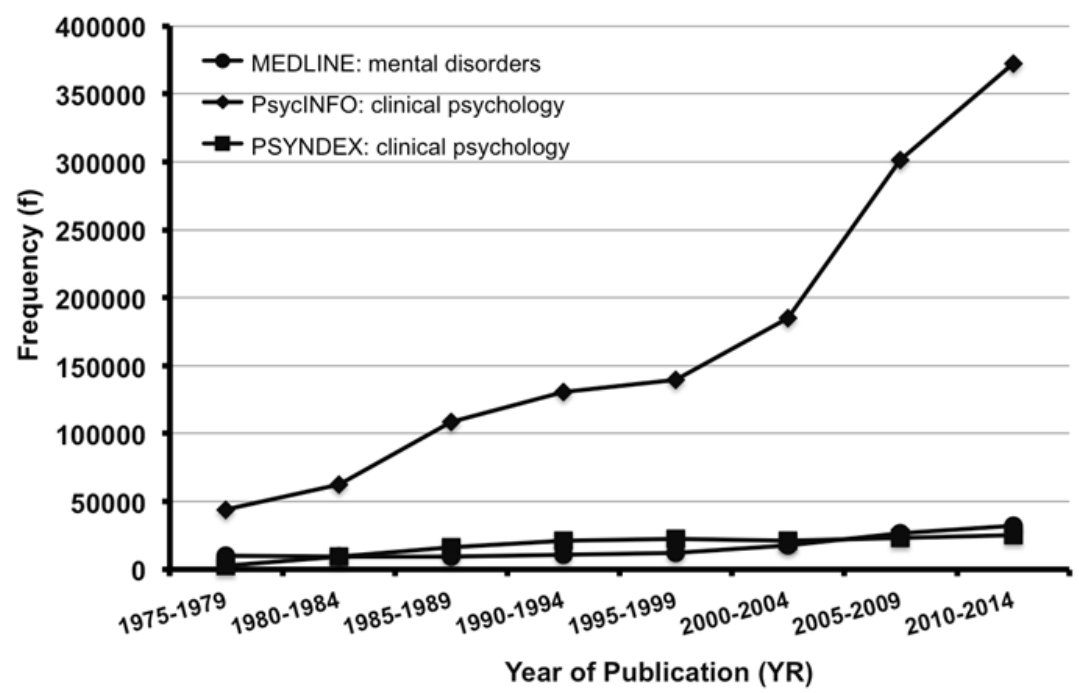

Figure 1. Absolute frequencies $(f)$ of publications with reference to ICD-10 chapter on mental disorders in MEDLINE as well as of clinical psychology publications documented in PsycINFO and PSYNDEX 1975-2014

\subsubsection{Coverage of the Databases}

The data presented in Table 2 also provides information about the coverage of the databases: for example, in the time period 2010-2014 MEDLINE covers only 9\% of PsycINFO; for all publications between 1975 and 2014 the quota is $10.5 \%$. PSYNDEX is neither directly comparable to MEDLINE nor to PsycINFO, because it is a complementary database for German- and English-language psychology publications from the German-speaking countries, which should be used supplementary to cover publications from these countries. This is necessary, because only $49 \%$ of the clinical psychology publications from the German-speaking countries documented in PSYNDEX are documented in PsycINFO as well, i.e., the other half is not. PsycINFO is largely dominated by publications from the Anglo-American countries (66\%); the remainder (34\%) comes from all over the world with a quota of $5 \%$ from clinical psychology in the German-speaking countries.

\subsubsection{Numbers of Clinical Case Studies in the Databases}

Numbers of clinical case studies documented in the databases between 1975 and 2014 can be found in the right column of Table 2. There are detectable increases in MEDLINE and PsycINFO: in the early 2010s there are 0.5 times more case studies in MEDLINE than in the late 1970s, in PsycINFO case studies increased about the factor 6. Data from PSYNDEX show another picture: at first, from the late 1970s up to the 1990s there is a similar increase of case studies as for PsycINFO (about 9 times more), but after the millennium there is a sharp drop down to only 30 case studies documented for the last quintile 2010-2014 (see Table 2 and Figure 2). 


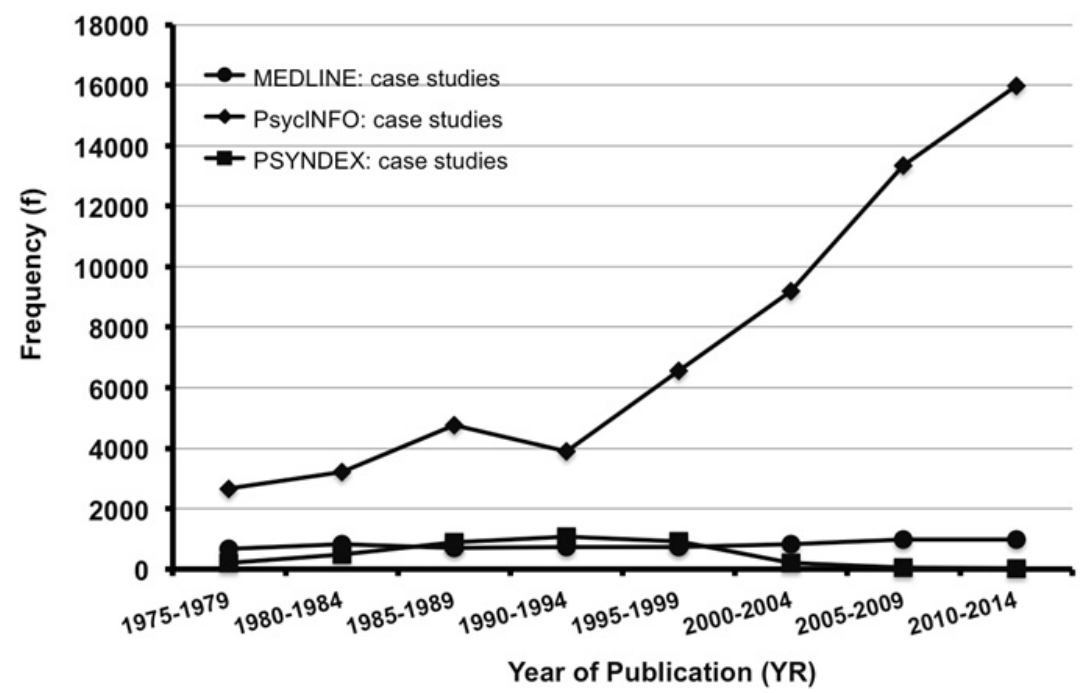

Figure 2. Absolute frequencies $(f)$ of case studies with reference to ICD-10 chapter on mental disorders in MEDLINE as well as of case studies with reference to clinical psychology publications documented in PsycINFO and PSYNDEX 1975-2014

\subsubsection{Growth Rates of Publications on Clinical Psychology in Total and on Clinical Case Studies}

The comparison of Figure 1 and Figure 2 leads to the impression that the growth rates of total clinical psychology literature and clinical case studies between 1975 and 2014 are quite similar. This is further supported by numerically high and statistically significant (Pearson) correlations for the growth rates in MEDLINE and PsycINFO, but not in PSYNDEX (see Table 3). Therefore, the analysis and description of absolute numbers and growth rates (see, e.g., Glänzel \& Schubert, 2015) is not sufficient. Necessarily, the absolute frequencies must be relativized to get the true picture (see below). The other correlation coefficients in Table 3 show that the growth rates between all — with one exception - absolute numbers documented in the three databases are significantly related. The increases of clinical psychology publications documented in MEDLINE, PsycINFO, and PSYNDEX as well as the increases of clinical case studies documented in MEDLINE and PsycINFO are similar (but at different absolute levels). One exception is the number of clinical case studies documented in PSYNDEX. Four statistically significant negative correlation coefficients (and one insignificant; see Table 3) underpin the already mentioned specifics of PSYNDEX, which must be reflected on in the discussion.

Table 3. Correlations (Pearson) of the absolute numbers of publications documented in MEDLINE on ICD-10 chapter "mental and behavioral disorders" (Version 2016) as well as of publications on case studies/reports within the chapter or clinical psychology, respectively, in the publication years 1975-2014

\begin{tabular}{|c|c|c|c|c|c|c|}
\hline \multirow[t]{2}{*}{ Database } & \multicolumn{2}{|c|}{ MEDLINE } & \multicolumn{2}{|c|}{ PsycINFO } & \multicolumn{2}{|c|}{ PSYNDEX } \\
\hline & $\begin{array}{c}\text { Total } \\
(f)\end{array}$ & Case studies $(f)$ & $\begin{array}{c}\text { Total } \\
(f)\end{array}$ & Case studies $(f)$ & $\begin{array}{c}\text { Total } \\
(f)\end{array}$ & Case studies $(f)$ \\
\hline \multicolumn{7}{|l|}{ MEDLINE: } \\
\hline \multicolumn{7}{|l|}{ Chapter Mental \& Behavioral Disorders } \\
\hline Total number & 1.00 & $.92 * *$ & $.97 * *$ & $.98 * *$ & $.62 * *$ & $-.70 * *$ \\
\hline Case studies & & 1.00 & $.90^{* *}$ & $.91 * *$ & $.57 * *$ & $-.67 * *$ \\
\hline \multicolumn{7}{|l|}{ PsycINFO: } \\
\hline \multicolumn{7}{|l|}{ Clinical psychology $\left(\mathrm{CC}=32 * \text { or } 33^{*}\right)^{\mathrm{b}}$} \\
\hline Total number & & & 1.00 & $.98^{* *}$ & $.78^{* *}$ & $-.53 * *$ \\
\hline Case studies & & & & 1.00 & $.72 * *$ & $-.62 * *$ \\
\hline \multicolumn{7}{|l|}{ PSYNDEX: } \\
\hline Clinical psychology $(\mathrm{CC}=32 * \text { or } 33 *)^{\mathrm{b}}$ & & & & & & \\
\hline
\end{tabular}




\begin{tabular}{ccc}
\hline Total number & 1.00 & .04 \\
Case studies & 1.00 & \\
\hline Note. $f=$ Absolute frequency; $* * p<.01$. &
\end{tabular}

Note. $f=$ Absolute frequency; $* * p<.01$.

${ }^{a}$ http://apps.who.int/classifications/icd10/browse/2016/en\#/V.

${ }^{\mathrm{b}} \mathrm{CC}=$ Classification codes (Thesaurus of Psychological Index Terms; Gallagher Tuleya, 2007).

\subsection{Relative Frequencies of Clinical Case Studies Published between 1975 and 2014 (MEDLINE, PsycINFO, and PSYNDEX)}

On the basis of the data presented in Table 1 (MEDLINE) and Table 2 (MEDLINE, PsycINFO, and PSYNDEX) the necessary relativization of the absolute numbers of clinical case studies upon the absolute total numbers of clinical psychology publications in 1975 to 2014 was carried out.

\subsubsection{MEDLINE: Relative Frequency of Clinical Case Studies in Some Medical Subdisciplines 1975-2014}

Figure 3 shows that the relative frequency of clinical case studies on mental and behavioral disorders documented in MEDLINE decreases rather continuously from the early 1980s (9\% of all documented publications) to the early 2010 s (3\%), i.e., sustaining a loss of $2 / 3$. The relative drop of case studies in all 21 ICD-10 chapters under view shows a very similar trend. It should be noted, however, that the developmental trends are very different in the various medical subdisciplines. This is illustrated in Figure 3 for publications on diseases of the skin and subcutaneous tissue, for which - at a high level—increases of case studies between the late 1970s (29\% case studies) and the early 2010s (37\%) took place. Publications on neoplasms are another example; here, the relative frequency of case studies seems to drop slightly, but at a rather stable level of about $9-10 \%$ (see Figure 3).

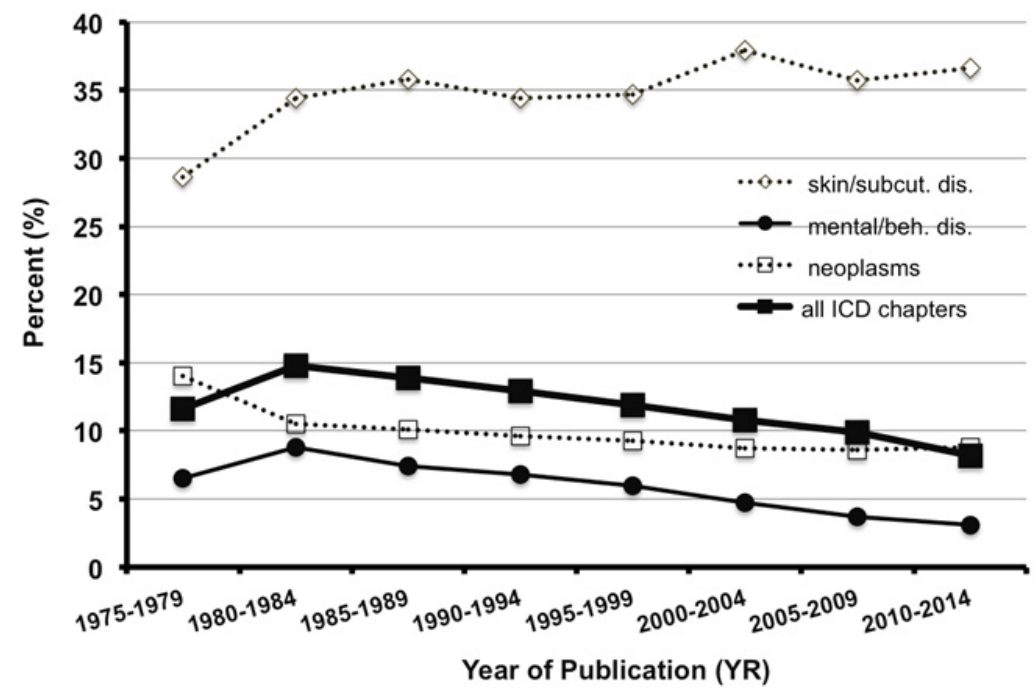

Figure 3. Relative frequencies (\%) of case studies with reference to all publications on all ICD-10 chapters and with reference to the specific chapters on mental disorders, diseases of the skin and subcutaneous tissue, and neoplasms in MEDLINE 1975-2014

\subsubsection{PsycINFO and PSYNDEX: Relative Frequency of Clinical Case Studies in Clinical Psychology 1975-2014}

Figure 4 shows that the developmental trend of the relative frequency of clinical case studies in clinical psychology documented in PsycINFO between 1975 and 2014 is V-shaped with 6\% in the 1970s, 3\% in the early $1990 \mathrm{~s}$, and $4-5 \%$ after the millennium. Thus, there is a rather continuous drop down to the early 1990s and a comeback around the millennium. After the millennium the initial level is nearly reached. 


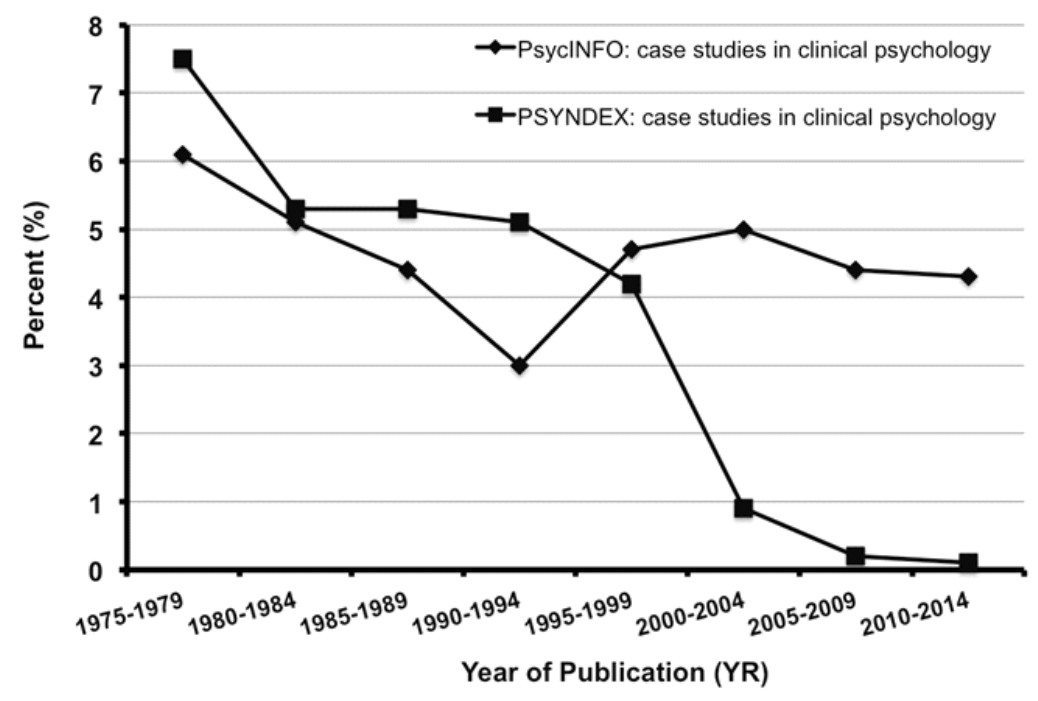

Figure 4. Relative frequencies (\%) of case studies with reference to all publications on clinical psychology documented in PsycINFO versus PSYNDEX 1975-2014

The developmental trend of case studies in clinical psychology publications from the German-speaking countries (PSYNDEX) shows a strong drop (see Figure 4). Starting with a high quota of 7.5\%, there is a first drop down to about $5 \%$ in the $1980 \mathrm{~s}$ and $1990 \mathrm{~s}$, and after the millennium a second sharp drop down to only $1 \%$. This suggests that clinical case studies seem to vanish from clinical psychology publications from the German-speaking countries.

\subsection{Excursus: Publication Trends of Non-Clinical Case Studies/Reports in Other Subdisciplines of Psychology}

It should at least be mentioned briefly that among the different psychological subdisciplines case studies/reports are most frequent in clinical psychology (PsycINFO: 95\%; PSYNDEX: 91\%). Nevertheless, in other than clinical subdisciplines (mainly applied ones like industrial and organizational psychology, educational psychology, consumer psychology, sport psychology, and forensics) case studies/reports exist with slight increases in their absolute number and relative frequency. Taken together their portion is $5 \%$ (PsycINFO) and $10 \%$ (PSYNDEX), respectively, of all case studies/reports.

\section{Discussion and Conclusion}

To summarize, the frequency of case studies/reports in clinical psychology publications has not increased in the last 40 years. Rather, the frequency has - with a serious drop in the early 1990s to 3\% - decreased a little: At present, $4-5 \%$ of all clinical psychology publications are case studies/reports. Thus, publication type and methodology of clinical case studies are not yet given up, but - nevertheless-there are some signs for that, especially when looking at MEDLINE and PSYNDEX, one database with a selective admission and coverage for publications on mental and behavioral disorders (MEDLINE), and the other with a defined exhaustive coverage for psychology publications from the German-speaking countries (PSYNDEX). PsycINFO shows the best coverage of clinical psychology publications, but it should be complemented by PSYNDEX to adequately consider the publications from the German-speaking countries. The majority of case studies/reports published in psychology are clinical; approximately $5-10 \%$ of the case studies/reports are non-clinical and published in other applied subdisciplines (with increasing frequency). Thus, publication type and methodology are specific for clinical psychology and (some) clinical psychologists are the proven experts, who may encounter and supervise the transfer of a sound case study/report methodology to other subdisciplines of psychology. At the time of our searches, 2014 was the last year for which complete database documentation could be expected. Thus, analyses should be repeated periodically to see how trends develop.

Referring to the subheading of our paper on trends concerning the frequency of publications of clinical case studies between 1975 and 2014 "Are we giving up a publication type and methodology in research on and teaching of psychopathology and psychotherapy" we tend to conclude with a cautious, therefore weak "nay, but". The scientometric results show a drop of the percentage of case studies on mental and behavioral disorders in 
MEDLINE and a sharp drop in PSYNDEX since the 1980s. Both databases have a limited coverage of the clinical psychology literature though: MEDLINE tries to cover all medical subdisciplines (i.e., all ICD-10 chapters), however, when compared to PsycINFO it is apparently not comprehensive, but very selective in the admission and documentation of publications on mental and behavioral disorders. By definition and production, PSYNDEX is a supplement to PsycINFO to cover psychology information from the German-speaking countries exhaustively. About one half of this information is also stored in PsycINFO, but the other half is not. PsycINFO shows the best coverage of clinical psychology publications, advantageously complemented by PSYNDEX to consider the entirety of publications from the German-speaking countries. PsycINFO data on the relative frequency of clinical case studies, however, raise hope that this type of publication and methodology is not given up in clinical psychology. The developmental trend in the time window under view is V-shaped, i.e., it starts in the late $1970 \mathrm{~s}$ with a quota of $6 \%$ case studies within the total clinical psychology literature, drops rather continuously to $3 \%$ in the early 1990 s, but recovers quickly up to $4-5 \%$ after the millennium. Still, an increase - corresponding to the scientometric results of a "dynamic growth" of case studies/reports in many sciences (Glänzel \& Schubert, 2015, p. 1) — cannot be observed for case studies in clinical psychology.

The results on the absolute and relative frequencies of clinical case study publications in the German-speaking countries are remarkable. Careful scientometric reanalyses and crosschecks performed independently by both authoring researchers as well as checks for changes in the inclusion criteria for psychology publications in PSYNDEX revealed no mistakes or artifacts. Hypothetically, there are at least three interpretations possible, which refer to the same time period and may reinforce themselves mutually.

The first interpretation refers to the very strong reception and acceptance of the phases of investigation model (see, e.g., United States National Institutes of Health, NIH; retrieved from https://www.clinicaltrials.gov/ and https://www.nlm.nih.gov/services/ctphases.html, respectively; US Food and Drug Administration, US FDA, 2015; https://www.accessdata.fda.gov/scripts/cdrh/cfdocs/cfcfr/CFRSearch.cfm?fr=312.21) in evidence-based and empirically supported psychotherapy in the German-speaking countries (especially in Germany itself). This model - originating from pharmacological research - distinguishes 4 to 5 phases of investigation, which are (0) exploratory studies, (1) pilot/screening studies, (2) controlled clinical trials, (3) multicenter studies, and (4) efficiency and generalizability studies. The orientation of clinical psychologists in the German-speaking countries towards this model was fostered by legislative processes and by enacting psychotherapy and psychotherapist qualification laws in the 1990s. As a consequence thereof, treatment effectiveness studies and treatment outcome studies for psychotherapy with high internal validity were required, i.e., phase-2-studies (randomized controlled trails) and-in addition-phase-3-studies (multi-center studies, meta-analyses) and phase-4-studies (generalizability efficiency or therapeutic use studies), to the detriment of phase-0-explorational and phase-1-screening studies, e.g., case studies/reports, because of their methodological weakness in the domains of internal validity and generalizability.

A second interpretation of the noticeable drop of clinical case studies publications in the German-speaking countries may refer to the efforts to (re-)internationalize and-therefore-to anglicize psychology publications from the German-speaking countries, which started in the late 1980s (see, e.g., Krampen et al., 2012). Clinical psychology researchers from these countries are highly motivated to publish in English-language journals (and succeed; see, e.g., Schui \& Krampen, 2015). They may hope to optimize their quota of "accepted for publication" rather by submitting results of controlled trials, meta-analyses, generalizability studies with large samples of patients, etc., than by submitting case studies/reports. The disregard of clinical case studies may be reinforced by hints arising from medical sciences and social sciences that "the mean citation rate of case studies/reports was uniformly less than the half of the category average" (Glänzel \& Schubert, 2015, p. 2).

Last, it should be mentioned that the enacting of psychotherapy and psychotherapist qualification laws in Austria, Germany and Switzerland in the 1980s to the 1990s led to a great reorganization and restructuring of clinical psychology education, training, and research. The leading clinical psychologists and researchers had to redefine their work and were involved much more in administrative and management duties including the implementation of controlled trials, generalizability studies, etc. (see above), but very frequently they distanced themselves from clinical practice (which — of course - is not in accordance with the guidelines and obligations of supervisors and psychotherapy lectures). Thus, it may be that there is simply not enough own "case experience" for the publication of serious clinical case studies. For example, in Germany psychotherapy trainees must write at least five detailed psychotherapy reports (i.e., clinical case studies) for their final examination and state-licensed psychotherapist approbation, but-however - these are not published.

Pros and cons of case studies/reports were and still are frequently discussed (see, e.g., Hyett et al., 2014; Flyvbjerg, 2006; Katzenstein et al., 2012), whereby the pros basically refer to the concreteness, contextuality, 
innovation potential, and respect of the singularity of the patient. The cons address rather monothematically the methodological weakness of (especially qualitative) case studies/reports in the domains of internal validity and generalizability (the last usually not being intended). Interesting in this context—and nice to read by the way —is Flyvbjerg's (2006) attempt to list and overcome five common misunderstandings about case study research in the social sciences. These misunderstandings match with repeatedly expressed stereotypes towards clinical case studies and they include (1) theoretical knowledge is more valuable than practical, (2) no generalizability, no contribution to scientific development, (3) useful only for hypotheses generation, not for hypotheses testing and theory building, (4) frequently biased toward "verification", and (5) difficulties of summarizing (writing) case studies.

Not surprisingly, when transferring the pharmacological phases of investigation model (see, e.g., United States National Institutes of Health, NIH; retrieved from https://www.clinicaltrials.gov/ and https://www.nlm.nih.gov/services/ctphases.html, respectively; US Food and Drug Administration, US FDA, 2015; https://www.accessdata.fda.gov/scripts/cdrh/cfdocs/cfcfr/CFRSearch.cfm?fr=312.21) to an evidence-based and empirically supported psychotherapy research, clinical case studies primarily fall into phase 0 (exploratory studies). This certainly holds true for the majority of narrative, qualitative case studies (Yin, 2011). Yet, quantitative clinical single case studies, e.g., with systematic interventional blending-masking-designs (see, e.g., Perone \& Hursh, 2013; Yin, 2014) can contribute substantially to investigation phases (2) single case controlled clinical trials and (4) single case efficiency studies in routine clinical practice. They can do this, however and surely, without fulfilling the criterion of generalizability of their results, but with empirical evidence for the applicability, meaningful differential indication, individual effectiveness, and efficiency of treatment techniques. Therefore, it may be valuable to combine qualitative (idiographic) and quantitative (nomothetic) methodology of case studies more systematically (Katzenstein et al., 2012). This can add to the reduction of vice versa stereotypes and promote teaching and clinical research of both methodologies, which — up to date - are described, taught, and applied rather separately (see, e.g., for qualitative case studies: Hinshelwood, 2013; Thomas, 2011; Yin, 2011; see, e.g., for quantitative case studies: Perone \& Hursh, 2013; Yin, 2014). It may be of advantage to not only have specialists for qualitative versus quantitative case studies/reports (who are each biased for stereotyping in research and teaching), but to have experts "in the middle of the road", who master and use both methodologies deliberately and combined depending on the question, possibilities, and objectives of research. This conforms very well to the classical principle of mesotes ( $\mu \varepsilon \sigma o ́ \tau \eta \zeta$, Greek: middle; Aristotle, 348-322 B.C.), which postulates that virtues are mostly in the middle between two poles (which both tend to be vices).

Considering the pros and cons of case studies/reports, their methodological constraints of low internal validity, insufficient generalizability, and subjectivity need to be balanced against their specific values in clinical training, applied research, and - as background - innovative research on the symptomatology, etiology, and classification of mental disorders as well as on combined and/or integrative treatment techniques and methods. Research on and treatment of bipolar affective disorder was initiated by Falret's (1854) careful long-time observations and clinical case studies of folie circulaire; "Little Hans" (Freud, 1909a), "Little Albert" (Watson \& Rayner, 1920) and "Little Peter" (Jones, 1924) were the first, for whom the symptomatology of phobia was described and theoretically explained with new psychotherapy techniques being explored and tested. This lasts up to our days (see, e.g., Pflug et al., 2012) and is most helpful for the development of novel, perhaps more effective, supplemental and/or less expensive and time-consuming treatment methods like attention bias modification (Bar-Haim, 2010) or computer-assisted behavioral therapy (Khanna \& Kendall, 2008). Therefore, clinical psychology should not—based on stereotypes and methodological biases — simply add case studies/reports to the garbage heap of merely historically relevant publication types and research methodologies. In the last three decades, recently, and in the near future clinical case studies were, are, and will be especially relevant for the development of a general, differential, i.e., an integrative psychotherapy (see, e.g., Frank et al., 1980; Grawe, 2004; Karasu, 1986; Weinberger, 1995), because it is important and cost-saving to explore and test novel and/or combined treatment methods and techniques in straightforward contexts. Case studies/reports should be viewed as an essential part of science. 


\section{References}

Aristotle. (n.d.). Nicomachean Ethics. Retrieved from http://www.virtuescience.com/nicomachean-ethics.html

Bar-Haim, Y. (2010). Attention bias modification (ABM): A novel treatment for anxiety disorders (Research review). Journal of Child Psychology and Psychiatry, 51, 859-870. http://dx.doi.org/10.1111/j.1469-7610.2010.02251.x

Beck, A. T., Wright, F. D., \& Newman, C. F. (1992). Cocaine abuse. In A. Freeman, \& F. M. Dattilo (Eds.), Comprehensive casebook of cognitive therapy (pp. 185-192). New York, NY: Plenum. http://dx.doi.org/10.1007/978-1-4757-9777-0_18

Berk, M. S., Henriques, G. R., Warman, D. M., Brown, G. K., \& Beck, A. T. (2004). A cognitive therapy intervention for suicide attempters: An overview of the treatment and case examples. Cognitive and Behavioral Practice, 11(3), 265-277. http://dx.doi.org/10.1016/S1077-7229(04)80041-5

Crowe, S., Cresswell, R., Robertson, A., Huby, G., Avery, A., \& Sheikh, A. (2011). The case study approach. BMC Medical Research Methodology, 11, 100. http://dx.doi.org/10.1186/1471-2288-11-100

Falret, J. P. (1854). Mémoire sur la folie circulaire (Paper on circular folly). Bulletin de l'Académie Impériale de Médicine, 19, 275-400.

Flyvbjerg, B. (2006). Five misunderstandings about case-study research. Qualitative Inquiry, 12(2), 219-245. http://dx.doi.org/10.1177/1077800405284363

Frank, J. D., Hoehn-Saric, R., \& Imber, S. D. (1980). Effective ingredients of successful psychotherapy. New York, NY: Brunner/Mazel.

Freud, S. (1905). Bruchstück einer Hysterie-Analyse (Dora) (Fragment of a hysteria analysis [Dora]). Monatsschrift für Psychiatrie und Neurologie, 18, 285-310.

Freud, S. (1909a). Analyse der Phobie eines fünfjährigen Knaben (Der kleine Hans) (Analysis of the phobia in a five-year-old boy [Little Hans]). Jahrbuch für psychoanalytische und psychopathologische Forschung, 1, 1-109.

Freud, S. (1909b). Bemerkungen über einen Fall von Zwangsneurose (Der Rattenmann) (Remarks on a case of compulsion neurosis [The ratman]). Jahrbuch für psychoanalytische und psychopathologische Forschung, 1, $357-421$.

Freud, S. (1918). Aus der Geschichte einer infantilen Neurose (Der Wolfsmann) (From the case of an infantile neurosis [The wolfman]). In S. Freud (Ed.), Sammlung kleiner Schriften zur Neurosenlehre (Bd. 4) (Collection of small papers on neuroses theory, Vol. 4). Leipzig: Barth.

Freud, S. (1920). Über die Psychogenese eines Falles von weiblicher Homosexualität (On the psychogenesis of a case of female homosexuality). Internationale Zeitschrift für Psychoanalyse, 6(1), 1-24.

Freud, S. (1928). Analyse d'une phobie chez un petit garçon de cinq ans (Le petit Hans). Revue Française de Psychanalyse, 2, 3 .

Freud, S. (1971). La relation of homme être rat: Un original cas histoire (The relationship of man to rats: An original case history). Revista de Psicoanálisis, 35(4), 475-526.

Freud, S. (1993). Dora: An analysis of a case of hysteria. New York, NY: Collier Books/Macmillian.

Gallagher Tuleya, L. (Ed.). (2007). Thesaurus of psychological index terms (11th ed.). Washington, DC: American Psychological Association.

Glänzel, W., \& Schubert, A. (2015). Foreword to the "Case Studies in Scientometrics" special issues. Scientometrics, 105, 1-3. http://dx.doi.org/10.1007/s11192-015-1755-7

Grawe, K. (2004). Psychological therapy. Cambridge, MA: Hogrefe \& Huber.

Hinshelwood, R. D. (2013). Single case studies, subjectivity and scientific knowledge. London: Routledge.

Hyett, N., Kenny, A., \& Dickson-Swift, V. (2014). Methodology or method? A critical review of qualitative case study reports. International Journal of Qualitative Studies on Health and Well-Being, 9, 23606. http://dx.doi.org/10.3402/qhw.v9.23606

Johansson, J., \& Öst, L.-G. (1981). Applied relaxation in treatment of "cardiac neurosis": A systematic case study. Psychological Reports, 48(2), 463-468. http://dx.doi.org/10.2466/pr0.1981.48.2.463 
Jones, M. (1924). A laboratory study of fear: The case of Peter. Pedagogical Seminary, 31, 308-315. http://dx.doi.org/10.1080/08856559.1924.9944851

Karasu, T. B. (1986). The psychotherapies: Benefits and limitations. American Journal of Psychotherapy, 40, 324-342.

Katzenstein, T., Pole, N., Ablon, J. S., \& Olsen, C. (2012). Combining idiographic and nomothetic approaches to single-case research. In R. A. Levy, J. S. Ablon, \& H. Kachele (Eds.), Psychodynamic psychotherapy research: Evidence-based practice and practice-based evidence (pp. 487-508). Totowa, NJ: Humana Press. http://dx.doi.org/10.1007/978-1-60761-792-1_28

Khanna, M. S., \& Kendall, P. C. (2008). Computer assisted CBT for child anxiety: The Coping Cat CD-ROM. Cognitive and Behavioral Practice, 15, 159-165. http://dx.doi.org/10.1016/j.cbpra.2008.02.002

Kovacs, M., \& Beck, A. T. (1978). Maladaptive cognitive structures in depression. The American Journal of Psychiatry, 135(5), 525-533. http://dx.doi.org/10.1176/ajp.135.5.525

Krampen, G. (2009). Introduction and some ideas as well as visions on an Open Access European Psychology Publication Platform. Psychology Science Quarterly, 51(Suppl. 1), 3-18. Retrieved from http://www.journals4free.com/link.jsp?1=15099544

Krampen, G., Huckert, T., \& Schui, G. (2012). Impact of anglicizing former German-language psychology journals on authorships and citation frequencies. European Psychologist, 17(3), 190-198. http://dx.doi.org/10.1027/1016-9040/a000074

Lesser, R. C., \& Schoenberg, E. (Eds.). (1999). That obscure subject of desire: Freud's female homosexual revisited. Florence, KY: Taylor \& Frances/Routledge.

Lewis, M. K., Rogers, C. R., \& Shlien, J. M. (1959). Time-limited, client-centered therapy: Two cases. In A. Burton (Ed.), Case studies in counseling and psychotherapy (pp. 309-352). Oxford, England: Prentice Hall. http://dx.doi.org/10.1037/10575-012

Öst, L.-G. (1985). Single-session exposure treatment of injection phobia: A case study with continuous heart rate measurement. Scandinavian Journal of Behavior Therapy, 14(3), 125-131. http://dx.doi.org/10.1080/16506078509456232

Öst, L.-G. (1992). Cognitive therapy in a case of choking phobia. Behavioural Psychotherapy, 20(1), 79-84. http://dx.doi.org/10.1017/S0141347300016360

Öst, L.-G., \& Käll, L.-G. (1977). Treatment of rat phobia with reinforced practice and fading: Two case reports. Scandinavian Journal of Behavior Therapy, 6(1), 25-38. http://dx.doi.org/10.1080/16506073.1977.9626684

Perone, M., \& Hursh, D. E. (2013). Single-case experimental designs. In G. Maddon, W. V. Dube, T. D. Timothy, G. P. Hanley, \& K. A. Lattan (Eds.), APA handbook of behavior analysis (Vol. 1, pp. 107-126). Washington, DC: American Psychological Association. http://dx.doi.org/10.1037/13937-005

Pflug, V., Seehagen, S., \& Schneider, S. (2012). Nichts Neues seit dem "kleinen Hans" und dem "kleinen Peter"? Psychotherapie der Angststörungen des Kindes-und Jugendalters (Nothing new since "Little Hans" and "Little Peter"? Psychotherapy for anxiety disorders in childhood and adolescence). Zeitschrift für Kinderund Jugendpsychiatrie und Psychotherapie, 40(1), 21-28. http://dx.doi.org/10.1024/1422-4917/a000146

Rogers, C. R. (1989). The case of Mrs. Oak. In D. Wedding, \& R. Corsini (Eds.), Case studies in psychotherapy (pp. 63-85). Itasca, IL: Peacock.

Rolls, G. (2015). Classic case studies in psychology (3rd ed.). New York, NY: Routledge/Taylor \& Francis.

Schui, G., \& Krampen, G. (2015). ZPID-Monitor 2012 zur Internationalität der Psychologie aus dem deutschsprachigen Bereich (ZPID monitor 2012 on the internationality of psychology in the $\begin{array}{llll}\text { German-speaking countries). } & \text { Psychologische } & \text { Rundschau, }\end{array}$ http://dx.doi.org/10.1026/0033-3042/a000234

Thomas, G. (2011). How to do your case study: A guide for students. Quebec, Canada: Presses de l'Université du Québec.

United States Food and Drug Administration (US FDA). (2015). Code of Federal Regulation Title 21: Section 312.21 Phases of an investigation. Washington, DC. Retrieved from https://www.accessdata.fda.gov/scripts/cdrh/cfdocs/cfcfr/CFRSearch.cfm?fr=312.21 
Watson, J. B., \& Rayner, R. (1920). Conditioned emotional reactions. Journal of Experimental Psychology, 3(1), 1-14 (Reprinted 2000, American Psychologist, 55(3), 313-317). http://dx.doi.org/10.1037/0003-066X.55.3.313

Weinberger, J. (1995). Common factors aren't so common: The common factors dilemma. Clinical Psychology: Science and Practice, 2(1), 45-69. http://dx.doi.org/10.1111/j.1468-2850.1995.tb00024.x

Yin, R. K. (2011). Qualitative research from start to finish. New York, NY: Guilford.

Yin, R. K. (2014). Case study research: Design and methods (5th ed.). Thousand Oaks, CA: Sage.

\section{Copyrights}

Copyright for this article is retained by the author(s), with first publication rights granted to the journal.

This is an open-access article distributed under the terms and conditions of the Creative Commons Attribution license (http://creativecommons.org/licenses/by/4.0/). 